\title{
NUEVA REVISTA CIENTÍFICA: IBERIA JUDAICA
}

\author{
POR \\ Carlos del Valle Rodríguez
}

Efectivamente, desde 2009 está siendo editada una nueva revista científica, en realidad se trata de un Anuario, consagrado exclusivamente al judaísmo hispano, antiguo y medieval. En principio podría parecer que es otra revista más de las múltiples que existen en el mundo científico. Si fuera así, ciertamente no tendría mucha razón de ser. Pero este nuevo Anuario tiene unas características propias, novedosas en el panorama internacional de los estudios hebreos hispánicos que lo hacen único e imprescindible. Como promotor de este nuevo proyecto editorial quiero explicar al lector las causas que han forzado a la génesis de esta nueva revista de investigación judaica.

No es ningún secreto para ningún estudioso ni para cualquier hombre ilustrado que el judaísmo no solamente tiene una vieja solera en la Península Ibérica, sino que ocupa una situación singular en la historia del judaísmo universal. Los grandes centros de producción literaria hebrea han sido Israel, Babilonia y España, que aún ahora sigue siendo investigada, analizada, editada y objeto de debate. Ningún otro país de la diáspora judía ha tenido una producción literaria tan copiosa y de tanta transcendencia, como Babilonia e Hispania.

Un talentoso literato e historiador, Moisés Ibn Ezra (m. ca. 1139) recoge una antigua tradición según la cual una parte de los judíos exiliados en Babilonia se vino directamente a Hispania cuando las autoridades babilónicas les permitieron abandonar su exilio. Lo que sí es cierto es que al menos desde el siglo i (d.C.) la presencia judía en España es indubitable. El Prof. H. Beinart trató de demostrar a través de las lápidas funerarias que la presencia judía en España quedaba fehacientemente probada desde el siglo i de la era cristiana. El problema, sin embargo, radica en que ninguna de aquellas lápidas está datada ni incluye tampoco indicios seguros de su ubicación temporal. ${ }^{1}$

\footnotetext{
${ }^{1}$ Beinart, Jaime, 1998. ¿Cuándo llegaron los judíos a España?», Estudios (Buenos Aires) 3: 5-32.
} 
El plan de San Pablo (m. ca. 60 d.C.) de pasar por Roma en su viaje a España (Epístola a los Romanos 15, 24.28) ha sido interpretado por muchos como una confirmación de la existencia de asentamientos judíos en España, ya que era una táctica misionera de San Pablo comenzar su evangelización por los lugares de asentamiento judío. De ahí que en la práctica el primer documento formal que atestigua la presencia judía en España es la Misná, el código legal judío que cierra su redacción en el siglo in de la era cristiana. En la Misná aparece España no sólo como un lugar hipotético a donde puede dirigirse un judío en un largo desplazamiento desde Palestina, de modo que se dé un largo plazo (de tres años) para la prescripción de las tierras y fincas que el desplazado haya dejado en Palestina (BB 3.2), sino también como una tierra de actividad empresarial y comercial en el área de la salazón de pescado, especialmente para «el atún español», con posible existencia de factorías para tales fines (Shab 22.2; Maksh 6.3). Cuando a principios del siglo iv (ca. 305) tiene lugar el Concilio de Elvira, sus cánones demuestran que la población judía estaba profundamente arraigada en España y con una red de contactos sociales muy extensa. ${ }^{2}$

Los datos pues documentales que tenemos es que los judíos se asientan en España en una época muy primitiva, al menos desde el siglo i de la Era Cristiana y que desde el principio desarrollan una actividad industrial y comercial relevante y que establecieron una tupida red de relaciones sociales con la población del país, especialmente con la cristiana. El hecho de que los sacerdotes cristianos asistan a las bodas judías, por ejemplo, o que los labradores cristianos llevaran a los rabinos a sus tierras y a sus fincas para que impetraran la bendición del cielo es sumamente revelador.

Pero hay otro elemento en la judería hispana de carácter transcendente que va a determinar y condicionar su periplo histórico. Por una parte la conciencia de su identidad nacional como pueblo y su lengua propia, irrenunciable, el hebreo.

Tenemos testimonios de que los judíos españoles disponían de una literatura propia. El rey Ervigio (m. 687) estableció una ley penando con la decalvación y con los azotes en plaza pública a todo aquel que leyere Iudeorum libros o los tuviere escondidos en sus casas. ${ }^{3}$ De la controversia de San Julián de Toledo (m. 690) con los judíos hispanos hay que deducir que los judíos hispanos tuvieron una literatura propia en hebreo. Los argumentos que según el arzobispo toledano se blandían en los códices hebreos hispanos en torno a las edades del mundo difieren notablemente de los ofrecidos en obras talmúdicas o midrásicas

2 Valle, Carlos del. 1998. «El Concilio de Elvira», La controversia judeocristiana en España: 15-19. Madrid:, Aben Ezra Ediciones.

${ }^{3}$ Zeumer, Karl. 1902. Monumenta Germaniae. Leges Visigothorum.: 438. Hannover-Leipzig. 
del ámbito de Palestian o Babilonia. Hay que deducir pues que se trata de una literatura autócona. ${ }^{4}$

Del cultivo entre los judíos españoles de la lengua hebrea hay un testimonio muy elocuente. Cuando el diácono de la Corte imperial, Bodón, que habiendo recibido inicialmente un permiso del emperador para dirigirse a Roma, cambia de rumbo y se viene a Zaragoza donde se convierte al judaísmo recibiendo el nombre de Eleazar y casándose con una judía de Zaragoza, mantiene una disputa a continuación con Álvaro de Córdoba (hacia el 820). Pues bien, Álvaro, en un momento de sus cartas, confiesa y queda sorprendido de que Bodón haya aprendido el hebreo en un espacio tan corto de tiempo, por el contacto y convivencia con sus nuevos correligionarios judíos de Zaragoza: Miror te eruditionis in hebraea lingua tam velox peritia. ${ }^{5}$

Probablemente unos años antes de la controversia de Bodón, emerge en la ciudad cordobesa de Lucena, Eleazar bar Samuel, que por sus conocimientos talmúdicos recibió los títulos de aluf y resh kal.la de las escuelas talmúdicas babilónicas, donde desarrolló una actividad docente. R. Eleazar es el primer sabio talmúdico de España, y de toda Europa, del que se nos han conservado algunas de sus obras (en hebreo-arameo). ${ }^{6}$ A partir de ese momento las relaciones epistolares entre los judíos españoles y las escuelas talmúdicas de Babilonia se hicieron muy intensas.

A partir del siglo x se produce un auténtico estallido de la producción literaria de los judíos españoles, de tal manera que hasta el momento de la expulsión (1492/1497) son centenares los autores hebreos españoles, en mi personal estimación en torno a los dos mil autores, que escriben mayormente en hebreo, una parte importante en árabe, algo en arameo, prácticamente nada en lengua romance. El hecho de que a los largo de más de medio milenio no se hiciera jamás una traducción de las obras capitales del judaísmo a la lengua romance y la circunstancia de que se compusieran en hebreo millares y millares de obras, me ha llevado al convencimiento personal de que el hebreo era una lengua viva entre los judíos españoles, es decir, una lengua que posibilitaba el rezo en hebreo en la sinagoga, el estudio y lectura de los libros del acervo cultural judaico y, evidentemente también la intercomunicación personal.

\footnotetext{
${ }^{4}$ Valle, Carlos del. 1898. «San Julián de Toledo», La controversia judeocristiana en España: 129. Madrid: Aben Ezra Ediciones. Valle, Carlos del. 1891. «El De Comprobatione sextae aetatis de Julián de Toledo», Estudios Bíblicos 49: 251-263.

${ }^{5}$ Valle, Carlos del. 2003. «Sobre las lenguas de los judíos en la España visigoda y al-Andalus»: Sefarad 63: 192. De la controversia de Bodón sólo nos ha quedado lo que nos transmite Álvaro en sus Cartas.

${ }^{6}$ Cfr. Rivlin, Joseph. 2011. «Rav Eleazar bar Samuel de Lucena, el primer hebreo hispano del que ha sobrevivido su obra», Iberia Judaica 3: 173-187.
} 
La religación histórica, ininterrumpida, de los judíos españoles con los centros creacionales del judaísmo rabínico de Palestina y Babilonia, ha dado al judaísmo español el marchamo de su autenticidad y de su legitimidad, desarrollando una inmensa literatura que, en muchos campos, tiene carácter imperecedero. Las tradiciones que los judíos españoles recogieron sobre la lengua hebrea son valiosísimas, a veces únicas. De ahí que su estudio y análisis será materia perdurable de investigación de las generaciones venideras, independientemente de las extraordinarias aportaciones de una pléyade de gramáticos hebraicos españoles. En el campo de la gramática hebrea, de la poesía hebrea, de la exégesis bíblica, de la jurisprudencia rabínica, de la cábala, incluso de la filosofía, la contribución de los judíos españoles ha sido importantísima, ciertamente de valor imperecedero.

Ésta es la razón por la que numerosos investigadores de las más variadas naciones investigan sin cesar los escritos de los hebreos españoles y sacan a la luz anualmente varios cientos de estudios sobre los mismos. En la propia España un grupo notable de estudiosos trabaja asimismo el inmenso legado cultural hebreo español y publica numerosos estudios, ediciones de textos, notas, comentarios.

No es un secreto para nadie que la investigación se autoalimenta con los estudios, análisis, inquisiciones, que hacen los distintos investigadores. Por eso el investigador necesita estar al día de las publicaciones que en su campo emergen, en su país y fuera de su país, y que sus propias contribuciones sean conocidas y, si es oportuno, sean puestas a debate público. Aquí es donde ha habido un grave problema en España. A pesar de que en ella hay varias revistas que tienen como su competencia el hebraísmo hispano, su historia, su cultura, su producción literaria, estas revistas no han dado importancia a la información bibliográfica ni tampoco a la crítica o a la reseña científica. El resultado es que un investigador residente en Madrid puede ignorar lo que ha publicado un colega suyo en Barcelona o en Granada o en cualquier otro lugar de España. Libros capitales en la historia del judaísmo, publicados en España, han sido ignorados por estas revistas de Judaica. En las revistas extranjeras del ramo tampoco se aborda adecuadamente esta problemática.

Ésta es la razón perentoria por la que hemos dado a luz a una nueva revista científica, un anuario, Iberia Judaica (2009-), donde no pueden faltar dos secciones vitales, el boletín bibliográfico y las reseñas de obras de Judaica, limitadas al judaísmo hispano antiguo y medieval. Para la elaboración del boletín se dispone de un equipo de corresponsales de diversas naciones (España, Austria, Italia, Alemania, EEUU). Lo ideal sería disponer de corresponsales en todos los países donde hay una producción científica importante (Israel, Francia, Reino Unido, Holanda, Países nórdicos...), pero, lamentablemente, los medios de que disponemos son muy escasos. En cuanto a las reseñas queremos que sean algo 
más que informativas, que supongan también un enriquecimiento del tema y una valoración y crítica de la investigación.

Otra falta, otra ausencia sentida en los estudios hebraicos y judaicos en España es la falta de textos de los propios autores hebreos. De ahí que una sección del anuario va a estar dedicada a ediciones de textos, en la lengua original o en traducción, de modo que el investigador pueda conocer al autor no solo a través de un estudio secundario, sino a través de los propios escritos del autor. En esta sección se han publicado ya, entre otros, los siguientes textos: Una respuesta de Lope de Barrientos sobre los conversos (2009, 231-246), un capítulo del Maasé ha-Efod de Profiat Durán sobre la lengua hebrea (2009, 247-254), la introducción de Abraham Ibn Ezra al Sefat Yeter (2009, 255-260), la sesión inicial de la Disputa de Tortosa en versión hispana antigua (2010, 203-216), la maldición de los herejes de Juan de Valladolid (2010, 217-232), una carta de Isaac ben al-Ahdab (2010, 243-250), un responsum de Ibn Adret $(2010,251,260)$, la disputa de Burgos de 1375 (2010, 233-242), 14 poemas hebreos en traducción sobre las persecuciones de 1391 (2011,77-113), el Marpe ha-lashon de Moisés ben Shem Tov Ibn Habib (2011, 129-144), la introducción de Abraham Ibn Ezra al libro de las Natividades $(2011,125-128)$, última voluntad de Ismael Ablitas el Mayor (2011, 117-124), responsa inéditas de Ibn Megas (2012, 219-222). Introducción y primeros capítulos del Tratado de Jerónimo de Santa Fe en versión catalana antigua $(2013,155-170)$, poemas de Bonafed $(2013,135-140) \ldots$

Otro problema que tienen las revistas es que se alimentan de colaboraciones espontáneas. El resultado es que los temas son tan dispersos, tan variados, que en muchas ocasiones carecen de interés para el investigador, no digamos ya si en la misma revista caben estudios de ugarítico, de fenicio, de hurrita, de antiguo sumerio, de antiguo egipcio... Por eso en Iberia Judaica cada número tiene un tema monográfico. En los cinco números hasta ahora publicados los temas monográficos han sido: Los judíos de al-Andalus, La polémica judeocristiana en España, Las persecuciones de 1391 en las elegías hebreas coetáneas, Abraham Ibn Ezra como científico europeo universal, Miscelánea de Judaica catalana.

Ciertamente creemos que el anuario Iberia Judaica ocupa un espacio necesario que estaba hasta ahora desatendido.

Espero que el lector, con las breves notas que aquí suministro, se haga consciente de la singularidad del nuevo Anuario y de su importancia para los estudios de judaísmo hispano, a nivel nacional e internacional, y le conceda ya de salida un plus de simpatía que necesita para que la nueva revista pueda asentarse y perdurar en el tiempo. 